\title{
Influence of Fermentation Methods on Neutral Detergent Fiber Degradation Parameters
}

\author{
D. Bossen, ${ }^{\star 1}$ D. R. Mertens, $\dagger$ and M. R. Weisbjergł \\ *Danish Agricultural Advisory Service, Danish Cattle Federation, Skejby, Denmark \\ †US Dairy Forage Research Center, Madison, WI \\ ‡University of Aarhus, Faculty of Agricultural Sciences, Foulum, Denmark
}

\section{ABSTRACT}

The effect of 3 fermentation methods, in situ (IS) in 4 lactating cows (average $\mathrm{pH}$ of 5.8), in vitro (IVn) with media $\mathrm{pH}$ of 6.8 , or in vitro (IVa) with media $\mathrm{pH}$ adjusted to 6.0 using citric acid, on fiber degradation parameters was studied using feeds ground to different particle sizes. Corn silage (CS), grass silage (GS), barley grain (B), sugar beet pulp (BP), and rapeseed cake (RC) were ground using a shear mill. Silages were ground through 8-, 4-, 2-, or 1-mm screens, B and BP through $4-, 2-$, or $1-\mathrm{mm}$ screens, and RC through 2- or 1-mm screens. The amylase-treated NDF (aNDF) content of samples ground using a 1-mm screen was 399, 431, 197, 480 , and $251 \mathrm{~g} / \mathrm{kg}$ of DM for CS, GS, B, BP, and RC, respectively, but increased with increasing screen size. Materials were incubated for $0,6,12,24,48$, and $96 \mathrm{~h}$ IS, IVn, or IVa. Inoculum for IVn and IVa was prepared as a composite from the cows used for IS. The potentially degradable aNDF $\left(\mathrm{D}_{0}\right)$, indegradable aNDF $(\mathrm{I})$, lag time (L), and fractional rate of degradation of potential degradable aNDF $\left(\mathrm{k}_{\mathrm{d}}\right)$ were estimated using PROC NLIN in SAS. Except for RC, fermentation methods affected most degradation parameters, especially $\mathrm{k}_{\mathrm{d}}$ and L. The IVn, IVa, and IS methods resulted in $\mathrm{k}_{\mathrm{d}}$ values of $0.291,0.105,0.080 \mathrm{~h}^{-1}$ and $0.262,0.107,0.103$ $\mathrm{h}^{-1}$ for BP and RC, respectively, demonstrating a decreasing rate of degradation for these feeds when fermented under suboptimal pH. In CS, GS, and B, no difference was found in $k_{d}$ between the IVn and IVa methods, which suggests that differences in $\mathrm{pH}$ did not alter $\mathrm{k}_{\mathrm{d}}$ in vitro. The $\mathrm{k}_{\mathrm{d}}$ values obtained for CS, GS, and $\mathrm{B}$ were $0.058,0.109,0.168$, and $0.028,0.054$, and $0.069 \mathrm{~h}^{-1}$ for the IVn and IS methods, respectively, indicating that the IS method using cows fed at production levels can underestimate the potential rate of NDF degradation. Using the IVa method, L was 12.1, 9.1, 7.8, and $2.5 \mathrm{~h}$ for CS, GS, BP, and RC, respectively, which

Received June 4, 2007.

Accepted December 19, 2007.

${ }^{1}$ Corresponding author: dob@agrotech.dk was higher than L obtained from the IVn and IS methods for all feeds except B, where L in all methods were near the parameter boundary of zero hour in NLIN. It was concluded that fermentation methods were more important than grinding screen size on estimates for feed aNDF degradation and that the individual aNDF degradation parameters for the 5 feeds were affected differently by fermentation methods.

Key words: degradation, neutral detergent fiber, kinetics

\section{INTRODUCTION}

New ration evaluation systems based on rumen nutrient degradation kinetics require methods that provide valid estimates of parameters for rumen nutrient degradation. Potential degradability and rate of NDF degradation are the most important feed characteristics for determination of feed/ration value, due to the large variation in NDF concentration and degradation among feeds (Huhtanen et al., 2006). The aim of feed evaluation is to describe the intrinsic feed factors determining degradation characteristics because the ration evaluation system should take into account the extrinsic factors that alter degradation kinetics in the actual feeding situation. It is therefore important that methods used for estimating degradation characteristics when evaluating feeds reflect the potential nutrient degradation in the ruminant.

Earlier studies indicate that methods (in situ, in vitro, in vivo) can differ considerably in estimated NDF degradation parameters (Huhtanen et al., 2006). However, in vivo measurements of digestion kinetics are few in number as this method is very resource demanding. Therefore, the in vitro (IV) method has been widely used in the United States (Mertens, 1993), whereas the in situ (IS) method has traditionally been used as basis for generating NDF degradation parameter estimates in Denmark (Weisbjerg and Hvelplund, 2005). The IS method is the basis for estimating NDF degradation parameters for the new common Nordic feed evaluation system (Eriksson et al., 2007). The IS and IV methods 
have strengths or weaknesses, dependent on whether the estimated feed degradation characteristics should express the actual or potential feed degradation, respectively. For example, the IS method may not estimate potential NDF degradation because results can be negatively effected by the rumen environment of the host animals as influenced by numerous factors as discussed in detail in review articles by e.g., Vanzant et al. (1998), Huntington and Givens (1995) and Nocek (1988). On the other hand, the IS method may predict actual degradation because it benefits from the feed being degraded in the rumen environment under typical feeding conditions. To be useful for feed evaluation, it is therefore essential to examine the behavior of the different methods for estimating the potential rate and extent of degradation and their alteration by factors like grinding.

The objective of this experiment was to examine the impact of screen size during grinding of samples and fermentation methods on estimates of aNDF degradation parameters, using samples of 5 common Danish feeds. For this examination the traditional IV method with media $\mathrm{pH}$ near 6.8 and the IS method using cows fed at production level were evaluated, in addition to an IV method where $\mathrm{pH}$ was lowered to about 6.0. The $\mathrm{pH}$ during IV incubation is known to have a significant effect on the aNDF degradation profile (Grant and Mertens, 1992b), and the latter method was included to evaluate effect of $\mathrm{pH}$ explaining some of the differences between the traditional IV and the IS methods used in this experiment.

\section{MATERIALS AND METHODS}

\section{Preparation of Feed Samples}

Samples of barley grain (B), sugar beet pulp (BP), rapeseed cake (RC), along with freeze-dried corn silage (CS) and grass silage (GS), were ground using a shear mill (Wiley mill, C.W. Brabender Instruments Inc., South Hackensack, New Jersey). Silages were ground through 8-, 4-, 2-, or 1-mm screens, B and BP through 4-, 2-, or 1-mm screens, and RC through 2- or 1-mm screens. Geometric particle size in the resulting 16 feed samples was calculated as prescribed by ASAE (2003) based on single measurements of sieve fraction mass distribution, using a sieve shaker particle separator system (Ro-Tap, Laval Lab Inc., Quebec, Canada) with 13 screens with apertures between 0 and 3,350 $\mu \mathrm{m}$.

\section{In Situ Incubation}

Four rumen-cannulated lactating Holstein cows ranging from 255 to 606 DIM, yielding from 12.7 to 20.0 $\mathrm{kg}$ of milk, were used for the IS incubation and as IV inoculum donors. Four cows were fed ad libitum 1 of 2 different mixed rations once daily at $0630 \mathrm{~h}$ during the total experimental period of $6 \mathrm{wk}$. On DM basis, the mixed rations (A, B) were composed of corn silage (30, $27 \%)$, alfalfa silage $(25,28 \%)$, a mix of concentrates (41, $45 \%)$, and alfalfa hay $(4,0 \%)$ and contained approximately (30, 28\%) amylase-treated NDF (aNDF) and $(18,17 \%)$ CP. Mix of concentrates for ration A consisted of 52\% medium ground corn, $15 \%$ roasted soybeans, $15 \%$ whole cottonseed, $8 \%$ soybean meal $(44 \% \mathrm{CP}), 6 \%$ corn gluten feed, $1 \%$ blood meal, $1 \%$ grease, and $2 \%$ vitamins and minerals (as-is). Mix of concentrates for ration $\mathrm{B}$ consisted of $74 \%$ coarse ground corn, $25 \%$ soybean meal $(44 \% \mathrm{CP})$, and $1 \%$ vitamins and minerals (as-is). The 2 cows fed ration A and B, respectively, had an average daily DMI of 21.9 and $27.8 \mathrm{~kg}$ per cow.

Samples for IS incubation were prepared by transferring $0.5 \mathrm{~g}$ of ground feed material into $5 \times 5 \mathrm{~cm}$ Dacron bags with a pore size of $50( \pm 15) \mu \mathrm{m}$. Sets of the 16 different feed samples and one empty bag (blank sample) were incubated for $6,12,24,48$, or $96 \mathrm{~h}$, respectively, in each of the 4 cows. Incubation was replicated after $2 \mathrm{wk}$. Within replicate, incubation of all samples was initiated at the same time at $1000 \mathrm{~h}$. Rumen $\mathrm{pH}$ was measured in all 4 cows before incubation, and every $3 \mathrm{~h}$ during the first $24 \mathrm{~h}$ of each IS incubation by collecting ruminal liquid in a small beaker from the cranioventral rumen and immediately measuring the $\mathrm{pH}$. After incubation, bags were rinsed in cold tap water and frozen. Immediately before analysis, samples were thawed at room temperature, and together with 4 sets of zero-hour samples (not presoaked), were washed twice in a washing machine for $13 \mathrm{~min}$ in approximately $20 \mathrm{~L}$ of water.

\section{In Vitro Incubation}

Sets of the 16 feed samples and a blank sample were incubated IV in duplicate for $6,12,24,48$, or $96 \mathrm{~h}$. This in vitro incubation (IVn) followed the procedure described by Goering and Van Soest (1970) with some modifications of both preparation of incubation medium and inoculum. The constituent solutions (micromineral solution, buffer solution, and macromineral solution) and the reducing solution used for incubation medium were prepared as follows:

Micromineral Solution. A total of $13.2 \mathrm{~g}$ of $\mathrm{CaCl}_{2} \cdot 2 \mathrm{H}_{2} \mathrm{O}, 10.0 \mathrm{~g}$ of $\mathrm{MnCl}_{2} \cdot 4 \mathrm{H}_{2} \mathrm{O}, 1.0 \mathrm{~g}$ of $\mathrm{CoCl}_{2} \cdot 6 \mathrm{H}_{2} \mathrm{O}$, and $8.0 \mathrm{~g}$ of $\mathrm{FeCl}_{3} \cdot 6 \mathrm{H}_{2} \mathrm{O}$ were dissolved in distilled water by agitation, and volume was brought to $100 \mathrm{~mL}$.

Buffer Solution. A total of $4.0 \mathrm{~g}$ of $\mathrm{NH}_{4} \mathrm{HCO}_{3}$ and $35.0 \mathrm{~g}$ of $\mathrm{NaHCO}_{3}$ were dissolved in $1.0 \mathrm{~L}$ of distilled water.

Macromineral Solution. A total of $5.7 \mathrm{~g}$ of $\mathrm{Na}_{2} \mathrm{HPO}_{4}$ - anhydrous, $6.2 \mathrm{~g}$ of $\mathrm{KH}_{2} \mathrm{PO}_{4}$ - anhydrous, 
and $0.6 \mathrm{~g}$ of $\mathrm{MgSO}_{4} \cdot 7 \mathrm{H}_{2} \mathrm{O}$ were dissolved in $1 \mathrm{~L}$ of distilled water.

Incubation Medium. A total of $2 \mathrm{~g}$ of trypticase, $400 \mathrm{~mL}$ of water, $0.1 \mathrm{~mL}$ of micromineral solution, 200 $\mathrm{mL}$ of buffer solution, $200 \mathrm{~mL}$ of macromineral solution, and $1 \mathrm{~mL}$ of resazurin were added in order and mixed.

Reducing Solution. A quantity of $625 \mathrm{mg}$ of cysteine hydrochloric acid was dissolved in $95 \mathrm{~mL}$ of water. Four milliliters of $1 \mathrm{~N}$ sodium hydrozide and $625 \mathrm{mg}$ of sodium sulfide nonahydrate were added and dissolved.

Immediately before initiating the IS incubation, ruminal fluid and contents from the 4 cows were collected in $1 \mathrm{~L}$ warmed and insulated beakers for preparation of IVn inoculum. After discarding the top layer of the collected ingesta from each cow, it was strained through 2 layers of cheesecloth to separate solids from liquids. From each cow, $250 \mathrm{~g}$ of rumen solids was mixed with $250 \mathrm{~mL}$ of incubation medium and $12.5 \mathrm{~mL}$ of reducing solution, blended for $1 \mathrm{~min}$, and then strained through 4 layers of cheesecloth together with $250 \mathrm{~mL}$ of rumen liquid. Twenty milliliters of the resulting 1:1 inoculum mixture was transferred to 125-mL Erlenmeyer flasks containing $0.5 \mathrm{~g}$ of feed sample, $30 \mathrm{~mL}$ of incubation medium, and $1.5 \mathrm{~mL}$ of reducing solution that was warmed in a $39^{\circ} \mathrm{C}$ water bath and had been purged with $\mathrm{CO}_{2}$ for a minimum of $30 \mathrm{~min}$. All IV fermentations were maintained under continuous $\mathrm{CO}_{2}$ pressure via a tube connected to each flask. The IVn incubation was replicated after $2 \mathrm{wk}$, initiating the first incubation (IVn-rep1) and the replicate (IVn-rep2) the same days, respectively, as the IS incubations. The $\mathrm{pH}$ of the 1:1 inoculum mixture of strained ruminal fluid and media from blended solids from all 4 cows was 6.89 and 6.38 for IVn-rep1 and IVn-rep2, respectively.

The same number of samples and replicates were used for a $\mathrm{pH}$-adjusted in vitro incubation (IVa) of feed samples. The IVa incubation was carried out the same way as described for the IVn incubation, only the $\mathrm{pH}$ of the incubation medium was reduced from 6.8 to 6.0 by adding $1 M$ citric acid (Grant and Mertens, 1992a). In this experiment, $60 \mathrm{~mL}$ of citric acid was added to $940 \mathrm{~mL}$ of original incubation medium to obtain 1,000 $\mathrm{mL}$ of adjusted incubation medium with a $\mathrm{pH}$ value of approximately 6.0. The IVa incubation (IVa-rep1) was initiated about $1 \mathrm{wk}$ after terminating IS and IVn incubations, and the replication (IVa-rep2) was initiated 1 wk after IVa-rep1. The $\mathrm{pH}$ of the 1:1 inoculum mixture was 5.89 and 6.05 for the IVa-rep1 and IVa-rep2, respectively. For all IV incubated samples the aNDF contents of the feeds were used as zero-hour aNDF-residue $\left(\mathbf{a N D F}_{\mathbf{0}}\right)$.

\section{Chemical Analysis}

Feed content of ash, CP, crude fat, starch, aNDF, and ADF are presented in Table 1. Feeds were analyzed according to conventional procedures. Ash was analyzed by heating to $525^{\circ} \mathrm{C}$ (AOAC, 2000), CP was calculated based on analysis of total N (Hansen, 1989), crude fat was analyzed by Soxhlet extraction with petroleum ether after hydrolyzing with $\mathrm{HCl}$ (Stoldt, 1952), starch was analyzed by enzymatic calorimetric technique (Knudsen et al., 1987), aNDF was analyzed by neutral detergent extraction (Mertens, 2002), and ADF was analyzed by acid detergent extraction (AOAC, 2000). The aNDF residue of IS incubated feed samples was analyzed using an Ankom ${ }^{200}$ Fiber Analyzer (Ankom Technology Corporation, Macedon, New York) following the user's instructions (Ankom Technology, 2005). Dacron bags $(5 \times 5 \mathrm{~cm})$ were used directly in the Ankom ${ }^{200}$ Fiber Analyzer. The aNDF content in feeds and the aNDF residues from IVn and IVa incubated feed samples were analyzed following the official AOAC method described by Mertens (2002), using Berzelius beakers with reflux. Using different methods for analyzing aNDF content between IS and IVn or IVa methods means that incubation method is confounded with analytical method.

\section{Calculations and Statistics}

The $\mathrm{pH}$ measurements from IV incubated samples were analyzed using Proc GLM in SAS (SAS Institute, 2000) applying model 1 :

$$
\begin{gathered}
\mathrm{Y}_{\mathrm{ijklm}}=\alpha_{\mathrm{i}}+\beta_{\mathrm{ij}}+\chi_{\mathrm{k}}+\delta_{\mathrm{l}}+\gamma_{\mathrm{m}}+\alpha \chi_{\mathrm{ik}}+\alpha \gamma_{\mathrm{im}} \\
+\chi \gamma_{\mathrm{km}}+\alpha \beta \gamma_{\mathrm{ijm}}+\alpha \chi \gamma_{\mathrm{ikm}}+\varepsilon_{\mathrm{ijklmn}} .
\end{gathered}
$$

In model $1, \mathrm{Y}$ is the $\mathrm{pH} ; \alpha_{\mathrm{i}}$ is fixed effect of method $(\mathrm{i}=\mathrm{IVn}, \mathrm{IVa}) ; \beta_{\mathrm{ij}}$ is fixed effect of replicates-withinmethod $(\mathrm{j}=1,2) ; \chi_{\mathrm{k}}$ is fixed effect of feed $(\mathrm{k}=\mathrm{CS}, \mathrm{GS}$, $\mathrm{B}, \mathrm{BP}, \mathrm{RC}) ; \delta_{1}$ is fixed effect of screen size used for grinding $(\mathrm{l}=1,2,4,8 \mathrm{~mm}) ; \gamma$ is fixed effect of incubation time $(\mathrm{m}=6,12,24,48,96 \mathrm{~h}) ; \alpha \chi_{\mathrm{ik}}, \alpha \gamma_{\mathrm{im}}, \chi \gamma_{\mathrm{km}}, \alpha \beta \gamma_{\mathrm{ijm}}$, and $\alpha \chi \gamma_{\mathrm{ikm}}$ are the respective interactions; and $\varepsilon_{\mathrm{ijklmn}}$ is the residual.

Degradation parameters for aNDF were estimated based on aNDF residues expressed in percent of DM, using the Marquardt method in Proc NLIN in SAS (SAS Institute, 2000) applying model 2:

$$
\text { aNDF residue }=\mathrm{I}+\left(\operatorname{aNDF}_{0}-\mathrm{I}\right) \times\left(\mathrm{e}^{-\left[\mathrm{k}_{\mathrm{d}} \times(\mathrm{t}-\mathrm{L})\right]}\right) .
$$

In model 2, I is the nonlinear parameter estimate of the indegradable fraction of aNDF (g/g of DM); $\mathrm{aNDF}_{0}$ is the amount of aNDF in the feed at time $=0 ; \mathrm{D}_{0}(=$ $\left.\mathrm{aNDF}_{0}-\mathrm{I}\right)$ is the potential degradable fraction of aNDF $\left(\mathrm{g} / \mathrm{g}\right.$ of DM); $\mathrm{k}_{\mathrm{d}}$ is the fractional rate of aNDF degradation $\left(\mathrm{h}^{-1}\right)$; $\mathrm{t}$ is time $(\mathrm{h})$; and $\mathrm{L}$ is the discrete lag time 
Table 1. Chemical composition of test feeds

\begin{tabular}{|c|c|c|c|c|c|}
\hline & Corn silage & Grass silage & Barley & Beet pulp & Rapeseed cake \\
\hline $\mathrm{DM}(\%)$ & 33.7 & 28.9 & 86.2 & 85.7 & 90.4 \\
\hline Ash & 3.19 & 11.26 & 2.25 & 10.53 & 7.16 \\
\hline $\mathrm{CP}$ & 8.9 & 17.7 & 11.2 & 10.5 & 32.3 \\
\hline Crude fat & 3.25 & 3.15 & 3.00 & 0.99 & 15.26 \\
\hline Starch & 29.3 & 0.4 & 49.0 & 0.7 & 0.8 \\
\hline aNDFom $^{1}$ & 38.3 & 40.3 & 19.9 & 42.0 & 25.5 \\
\hline $\mathrm{ADF}$ & 21.0 & 27.7 & 5.7 & 24.2 & 19.4 \\
\hline
\end{tabular}

${ }^{1}$ Ash-corrected amylase-treated NDF.

(h). Following the recommendations of Weisbjerg and Lund (2004), duplicate measurements of aNDF residues at the same incubation time within IV method and replicate were averaged before parameter estimation. For the IS method, the aNDF residue of the 4 cows at each fermentation time within replicate was averaged before parameter estimation. This approach resulted in one set of degradation parameters per replicates-within-method. For each set of degradation parameters, the effective degradation (ED) of aNDF was calculated to provide the combined influence of all aNDF degradation parameters on aNDF degradation. The ED was calculated using the revised formula of McDonald (1981) that includes the effect of lag time as described by Mertens (1977) and Stensig et al. (1994), based on a 1-compartment model for rumen fiber turnover assuming the rumen fractional rate of passage $(\mathrm{k})$ to be $0.02 \mathrm{~h}^{-1}$ (formula 1). More complicated models for description of rumen fiber turnover might better express the actual aNDF degradation (Lund et al., 2007).

$$
\text { Formula 1: } \mathrm{ED}=\mathrm{D}_{0} \times \mathrm{k}_{\mathrm{d}}\left(\mathrm{k}+\mathrm{k}_{\mathrm{d}}\right) \times \mathrm{e}^{-\mathrm{kL}} .
$$

Initial statistical data analysis using a full model including feed, method, grinding, and all 2-factor interactions showed that feed interacted with all other variables investigated. Therefore, to investigate the influence of sample grinding and fermentation method, statistical analyses were carried out within feed. Estimates of aNDF degradation parameters were analyzed in SAS (SAS Institute, 2000), using Proc GLM applying model 3 :

$$
\mathrm{Y}_{\mathrm{ijk}}=\alpha_{\mathrm{i}}+\delta_{\mathrm{j}}+\alpha \delta_{\mathrm{ij}}+\varepsilon_{\mathrm{ijk}} .
$$

In model 3 , $\mathrm{Y}$ represents $\mathrm{I}, \mathrm{D}_{0}, \mathrm{k}_{\mathrm{d}}$, $\mathrm{L}$, or $\mathrm{ED}$, respectively; $\alpha$ is the fixed effect of incubation method ( $\mathrm{i}=$ IVn, IVa, IS); $\delta$ is the fixed effect of screen size used for grinding $(\mathrm{j}=1,2,4,8 \mathrm{~mm}) ; \alpha \delta_{\mathrm{ij}}$ is the interaction between method and grinding; and $\varepsilon_{\mathrm{ijk}}$ is the residual.
The $P$-values presented refers to the $F$-test of model 3 . The Waller-Duncan k-ratio $t$-test was used for mean separation when $F$-test had a $P<0.05$. The mean separation test used the main factor interaction $\left(\alpha \delta_{\mathrm{ij}}\right)$ as the error term. This conservative approach was chosen because grinding might be perceived as a split-plot factor and because of the occurrence of interactions between the main factors in model 3 for a few parameters within some feeds.

\section{RESULTS AND DISCUSSION}

\section{Grinding and Particle Size}

Grinding through the same screen size generated different geometric mean particle sizes for the 5 feeds, as illustrated in Figure 1a. Some concentrate feeds (BP and B) ground at a 4-mm screen had a higher geometric particle size than silages (GS, CS) ground at a 8-mm screen. Similar results are reported by Michalet-Doreau and Cerneau (1991) who found significantly different mean particle sizes among concentrates in response to grinding through same screen size. As discussed in the review of Huntington and Givens (1995), feeds disintegrate differently to grinding due to differences in physical structure. The distributions of particle size resulting from grinding are dependent on the proportion of the constituent plant parts (leaf:sheath:stem ratio), but different plant species also may behave differently (Huntington and Givens, 1995). In cereal and corn whole-crop forages, the seed fraction might disintegrate differently compared with vegetative plant parts.

\section{Correction of aNDF Residues}

A significant increase in weight of IS incubated blank samples (empty bags) with increasing incubation time was found. Average dry weight change of 8 blank replicates ( 4 cows $\times 2$ replicates) were $-0.7,-0.2,0.4,0.4$, 1.0 , and $2.5 \mathrm{mg}$ at $0,6,12,24,48$, and $96 \mathrm{~h}$, respectively. After ND extraction, the blank samples weighed less than they did initially. Although there was a tendency 
A
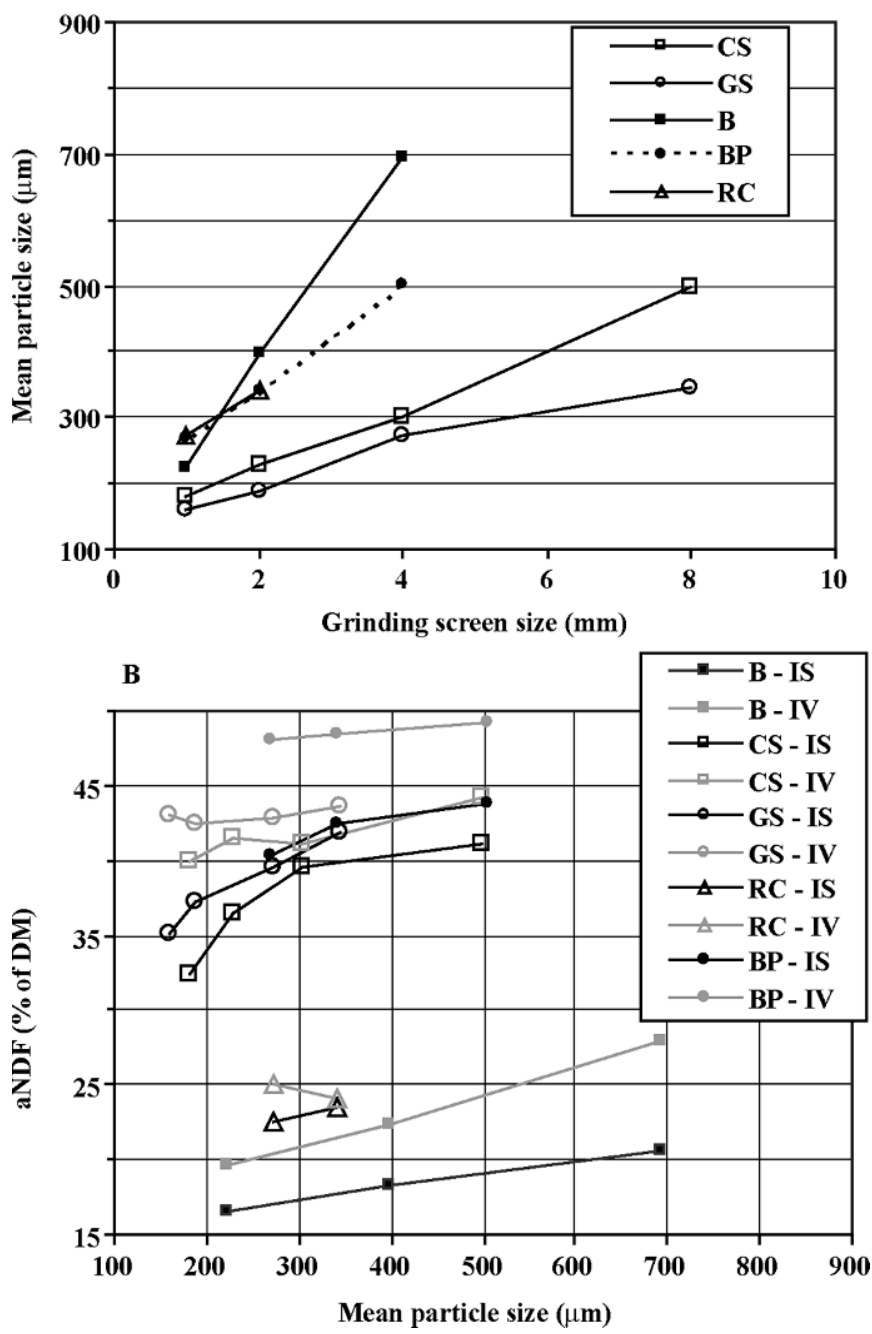

Figure 1. A: Mean particle size from grinding barley (B), corn silage (CS), grass silage (GS), rapeseed cake (RC), and beet pulp (BP) through different screen sizes. B: Zero-hour aNDF content from in vitro (IV, gray lines) and in situ (IS, black lines) measurement of the 5 feeds dependent on mean particle size.

for weights of blank samples after ND extraction to increase with time, it was not significant. Therefore, aNDF residues of IS-incubated samples were corrected with the average weight change during incubation and ND extraction of blank samples across all incubation times within replicate. It was -2.9 and $-5.2 \mathrm{mg}$ for replicate 1 and 2, respectively. Although small, these corrections account for up to $50 \%$ of the aNDF residue after fermentation (e.g., BP incubated for $96 \mathrm{~h}$ ). Small amounts of aNDF originating from the rumen fluid were found in IV-incubated blank samples, but it was not influenced by incubation time. Due to these findings, the aNDF residues in IV incubated samples were corrected with the average aNDF residue found in blank samples within replicates averaging $7.7 \mathrm{mg}$.

\section{Zero-Hour aNDF Content}

The aNDF ${ }_{0}$ content of both IV and IS methods increased with increasing particle size, as illustrated in Figure 1b, especially for B and CS. Using samples of dried winter wheat straw ground to pass 4.5-, 1.0-, and 0.25-mm screens, respectively, Udén (1992) found no difference in $\mathrm{NDF}_{0}$. In contrast, Mertens (2002) mentions that the finer ground samples in general are extracted more completely. The AOAC method (Mertens, 2002) for aNDF determination is validated for samples ground at 1-mm screen size and for feeds with starch content up to $50 \%$ of DM. The starch content of B used in this experiment was close to this upper starch limit. We observed increasing difference between $\mathrm{aNDF}_{0}$ and the aNDF residue after $6 \mathrm{~h}$ of incubation as particle size increased in samples of $\mathrm{B}$ and CS. The higher $\mathrm{aNDF}_{0}$ with increasing particle size (Figure $1 \mathrm{~b}$ ) and rapid loss of aNDF residue during the first $6 \mathrm{~h}$ of fermentation suggest that starch was extracted incompletely from $\mathrm{aNDF}_{0}$ in $\mathrm{B}$ when grind size exceeded 1 $\mathrm{mm}$.

Figure $1 b$ illustrates that $\mathrm{aNDF}_{0}$ was higher in IV samples analyzed using the Berzelius beakers with reflux (gray lines), compared with IS samples analyzed in the Dacron bags (black lines), probably due to particle loss from the bags during the washing procedure when using the IS method. For CS, GS, BP, and RC, the difference between the IS and the IV methods tended to decrease as particle size increased, indicating a reduced loss of particles during the washing procedure as particle size increased. In B, the influence of starch contamination might exceed the influence of particle loss on measurements of $\mathrm{aNDF}_{0}$, which may explain the increasing difference in $\mathrm{aNDF}_{0}$ found between IS and IV as particle size increased.

\section{pH During Incubation}

The LS means for $\mathrm{pH}$ of the media after fermentation were 6.7 and 6.0, for IVn and IVa respectively, which were close to target values of 6.8 (IVn) and 6.0 (IVa). There was a significant interaction $(P<0.0001)$ between replicate-within-method and incubation time affecting ending incubation $\mathrm{pH}$. The influence of replicateswithin-method could be due to variation in microbiological activity of the inoculums (Rymer et al., 2005). However, the magnitude of this interaction was in general small, averaging $<0.1 \mathrm{pH}$ between replicates. Significant interactions were also found between feed, method, and incubation time as illustrated in Figure 2. It appears that the environment in the flasks developed differently, dependent on the feed and method $\mathrm{pH}$ (IVn vs. IVa). The decrease in $\mathrm{pH}$ during incubation mainly depends on the amount of fermentation acids produced 

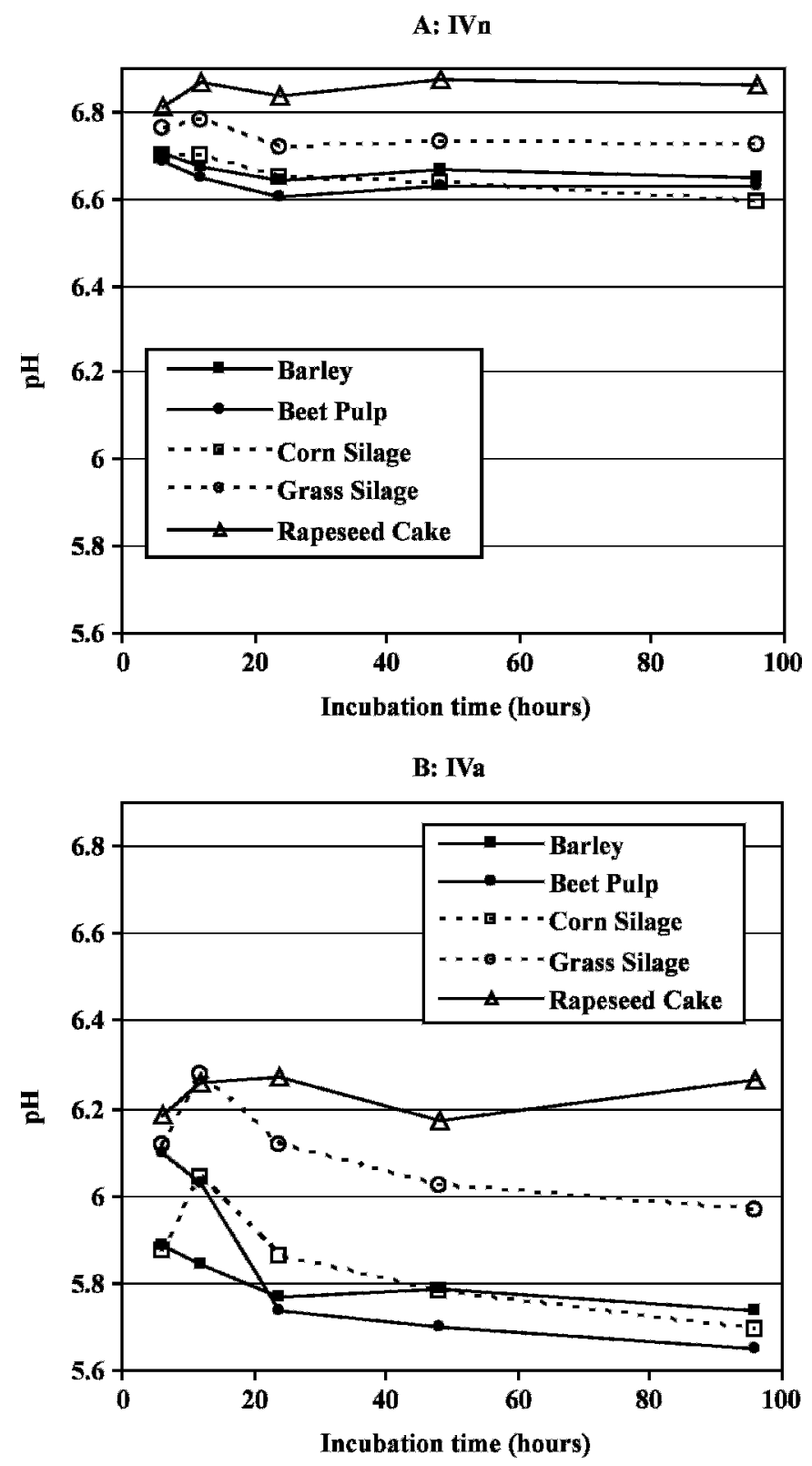

Figure 2. Average $\mathrm{pH}$ of 2 replicates during incubation up to 96 $\mathrm{h}$ under normal (A) and $\mathrm{pH}$ adjusted (B) fermentation methods for barley, corn silage, grass silage, rapeseed cake, and beet pulp.

and thereby the fermentability of the incubated feeds. For normal (IVn) as well as $\mathrm{pH}$-adjusted (IVa) methods, GS and RC generated higher $\mathrm{pH}$ during the entire incubation interval compared with the other feeds, and RC often had $\mathrm{pH}$ above the initial incubation $\mathrm{pH}$. Perhaps the high IV $\mathrm{pH}$ of these feeds was due to ammonia release during protein degradation. The difference in $\mathrm{pH}$ development during incubation among feeds could arise from differences in buffering capacity of the feeds (Jasaitis et al., 1987). Grant and Mertens (1992b) also found different changes in incubation medium $\mathrm{pH}$ between feeds as fermentation progressed, when comparing alfalfa hay, bromegrass hay, and corn silage. They observed the largest changes for corn silage, where initial $\mathrm{pH}$ of $6.8,6.2$, and 5.8 after $96 \mathrm{~h}$ of incubation declined to $6.65,6.15$, and 5.66, respectively. Their results do not indicate that changes in $\mathrm{pH}$ during incubation were dependent on initial $\mathrm{pH}$ level, as found in our experiment where differences in $\mathrm{pH}$ among feeds and among incubation times within feed were greater for IVa compared with IVn (Figure 2; e.g., for CS the initial $\mathrm{pH}$ was 6.8 and 6.0 and after $96 \mathrm{~h}$ of incubation was reduced to 6.58 and 5.68, respectively). In the experiment of Grant and Mertens (1992b), pH was reduced from 6.8 to 6.2 or 5.8 by replacing 18 and $40 \mathrm{~mL}$ of a $1,000-\mathrm{mL}$ batch of incubation medium, respectively, with $1 M$ citric acid. In our experiment, $60 \mathrm{~mL}$ out of $1,000 \mathrm{~mL}$ of incubation medium was replaced by $1 M$ citric acid to obtain $\mathrm{pH}$ 6.0, which might have reduced the medium buffer capacity compared with that used by Grant and Mertens (1992b), and resulted in larger $\mathrm{pH}$ changes during incubation of some feeds.

A significant $(P<0.05)$ effect of grinding screen size within feed showed that ending $\mathrm{pH}$ in general was lower the finer the feeds were ground, but numerically the differences in ending $\mathrm{pH}$ between grinding sizes were low ( 0.01 to $0.03 \mathrm{pH}$ unit) and of little importance compared with the influence of the other factors.

Average $\mathrm{pH}$ measured in the 4 cows during the first 24-h period of IS incubation is presented in Figure 3. Within the total 24 -h period the average $\mathrm{pH}$ was 5.8 , but there was a large diurnal variation in $\mathrm{pH}$ during IS incubation. Neither the replicate effect nor the replicate by time interaction were significant for IS ruminal $\mathrm{pH}$. However, cow, cow $\times$ time, and cow $\times$ replicate interactions were different $(P<0.01)$, indicating the value of replicating results and averaging observations across cows within replicate to accurately detect differences among methods, feeds, or grinds.

\section{aNDF Degradation Parameters}

A total of 768 IS and 672 IV samples were analyzed for aNDF. Thirty-eight IV-incubated samples were classified as defective and deleted, including 22 samples with mistakes during analysis and 16 samples identified as outliers. Outliers of IV samples were identified using a 2-step procedure. Initially average and standard deviation were calculated for replicated results obtained for the same feed within method (IVa, IVn), grind size, and incubation time. Where the standard deviation exceeded $20 \mathrm{~g}$ of aNDF/ $\mathrm{kg}$ of DM (corresponding to standard deviations in the upper $10 \%$ quantile), outliers of IV samples were identified as the individual 


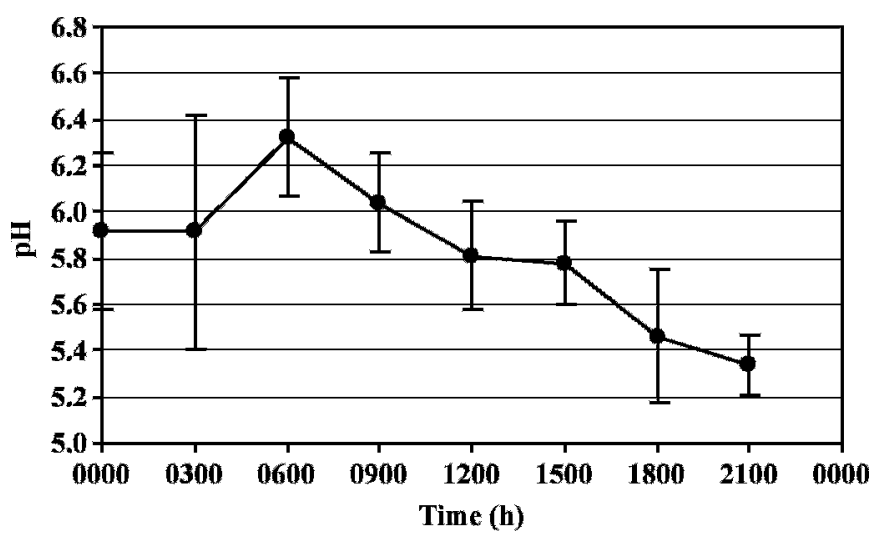

Figure 3. Average diurnal rumen $\mathrm{pH}$ of 4 cows used for in situ incubation during 2 replicates.

result differing more than 1 standard deviation unit from the average for that replicate. Thirteen IS incubated samples were classified as defective and deleted, including 2 samples lost during analysis and 11 samples identified as outliers. Outliers of IS samples were identified using the same 2-step procedure as for IV samples, except that the initial calculation of average and standard deviation were based on replicated results obtained for the same feeds within grind size and incubation time. Where the standard deviation exceeded 40 $\mathrm{g}$ of aNDF/ $\mathrm{kg}$ of DM (corresponding to standard deviations in the upper 10\% quantile), outliers of IS samples were identified as the individual result differing more than 1 standard deviation unit from the average for that replicate. Outliers were removed before means within replicate, method, feed, and grind were calculated for nonlinear estimation of degradation parameters. For either method, less than $2.5 \%$ of the results were outliers, but these spurious results could have had a dramatic impact on the estimation of kinetic parameters. In total, 96 sets of degradation parameters were estimated ( 2 sets of degradation parameters per method, 3 methods per feed sample, and 16 feed samples). Influence of method and sample grinding on aNDF degradation parameters are presented in Tables 2, 3, and 4 .

Interpretation of Interactions. Initial statistical analysis using a full model including feed, method, grinding, and all 2-factor interactions showed that feed interacted with method $(P<0.0001$ for all degradation parameters) and grind ( $P<0.0001$ for $\mathrm{D}_{0}$ and $\mathrm{ED}$, but not significant for other parameters). Because of these interactions and the focus of the research on differences due to sample grinding and fermentation method, the final statistical analysis was carried out within feed. Feed $\times$ method interactions were also reported by Dewhurst et al. (1995). Analyzing 15 plant-derived feeds, Dewhurst et al. (1995) observed significantly higher
OM fermentability after $2,4,8,24$, and $48 \mathrm{~h}$ of IS incubation compared with IV incubation, using nonlactating cows fed a daily basal diet of $4.1 \mathrm{~kg}$ of concentrate and $2.8 \mathrm{~kg}$ of grass hay for IS incubation. They attributed the difference between methods to feed ADF content because the differences in OM fermentability increased as ADF content decreased. Loss of fine particles from the IS bags, especially from feeds that contain little fiber, is the likely cause for this interaction, and this possibility is also mentioned by Dewhurst et al. (1995).

Interactions between grinding screen size and method were observed for the ED and aNDF degradation parameters of some feeds (Table 2). The interactions between method and grinding for ED of GS and $B$ were created by the significant interactions for the kinetic parameter $\mathrm{D}_{0}$ for these feeds. The highly significant interaction $(P=0.0001)$ between method and grinding for $\mathrm{D}_{0}$ of $\mathrm{B}$ occurred because $\mathrm{D}_{0}$ increased markedly as screen size used for grinding increased, and this tendency was more pronounced in IV compared with IS methods. This interaction could be caused by starch contamination of the aNDF ${ }_{0}$ because $\mathrm{D}_{0}$ is the difference between $\mathrm{aNDF}_{0}$ and $\mathrm{I}$, which should not be affected by starch contamination after $96 \mathrm{~h}$ of incubation. Less significant interactions $(P<0.05)$ between method and grinding for $\mathrm{D}_{0}$ were found in GS and for $\mathrm{L}$ in BP. In GS, $\mathrm{D}_{0}$ decreased with decreasing particle size for IS incubated samples, whereas $\mathrm{D}_{0}$ was almost independent of particle size in IV incubated samples. Mean particle size of GS was small, resulting in loss of $\mathrm{D}_{0}$ and to a lesser extent I for IS compared with IV when grinding screens had apertures $<2 \mathrm{~mm}$.

Influence of Diet, Cow, and Time of Inoculum Collection. Multiple cows and diets were used to provide diversity in the microbial population for IS and IV fermentations. To make comparisons consistent with the composite inoculum used for IV fermentations, parameter estimates for IS were based on the average residues measured in the 4 cows fed 2 different diets. Our experimental design replicated the results of IS, IVn, and IVa methods, and the variation of replicatewithin-method is a part of the error term used to detect differences. In general, replicate-within-method variation was greater than variation within-replicates, providing more conservative estimates of probabilities of differences among methods.

Because IVn-Rep1, IVn-Rep2, IVa-Rep1, and IVaRep2 were run on wk 1, 3, 5, and 6 of this experiment, the effects of method and time of inocula collection are confounded. However, the 4 cows used to generate a composite inoculum were fed the same diets throughout the experiment, which should minimize any systematic differences in inocula over time. The average $\mathrm{pH}$ of the 
Table 2. $P$-values for statistical significance of interactions between method and grinding on amylasetreated NDF (aNDF) degradability parameters

\begin{tabular}{lccccc}
\hline Item $^{1}$ & Corn silage & Grass silage & Barley & Beet pulp & Rapeseed cake \\
\hline $\mathrm{D}_{0}, \mathrm{~g} / \mathrm{g}$ of $\mathrm{DM}$ & 0.9 & 0.03 & 0.0001 & 0.06 & 0.4 \\
$\mathrm{k}_{\mathrm{d}}, \mathrm{h}^{-1}$ & 0.8 & 0.07 & 0.5 & 0.4 & 0.6 \\
$\mathrm{I}, \mathrm{g} / \mathrm{g}$ of $\mathrm{DM}$ & 0.7 & 0.06 & 0.2 & 0.1 & $>0.9$ \\
$\mathrm{~L}, \mathrm{~h}$ & 0.9 & 0.2 & 0.6 & 0.01 & 0.8 \\
$\mathrm{ED}, \mathrm{g}$ of aNDF/g of $\mathrm{DM}$ & 0.8 & 0.02 & $<0.0001$ & 0.9 & 0.2 \\
\hline
\end{tabular}

${ }^{1} \mathrm{D}_{0}$ is the potentially degradable fraction of aNDF, $\mathrm{I}$ is the indegradable fraction of aNDF, $\mathrm{L}$ is the lag time, $\mathrm{k}_{\mathrm{d}}$ is the fractional rate of degradation of potential degradable aNDF, and ED is the effective aNDF degradation.

ruminal contents used to create the inocula was not different among cows or runs $(5.8,5.6,5.9$, and 5.9 for IVn-Rep1, IVn-Rep2, IVa-Rep1, and IVa-Rep2, respectively) suggesting the inocula were similar. To evaluate systematic differences in inocula, the differences in results between IVn-Rep2 and IVa-Rep1 or IVa-Rep2 and between IVn-Rep1 and IVa-Rep1 or IVa-Rep2 provided estimates of IVn versus IVa comparisons that were 2, 3,4 , or 5 wk apart in time of inoculation. There was no significant trend in these method differences, which also indicates no systematic change in inoculum during the time of this experiment. Although there is confounding in method and time of inocula collection in our experiment, we postulate that the difference in results for IVn and IVa method is due primarily to differences in the in vitro fermentation conditions (media $\mathrm{pH}$ of 6.7 or 6.0 for IVn and IVa, respectively). This conclusion agrees with that of Grant and Mertens (1992b) who compared in vitro fermentations at different $\mathrm{pH}$ using the same inoculum.

Influence of Incubation Method. Incubation method affected all degradation parameters for all feeds

Table 3. Influence of the method on the degradation parameters of amylase-treated NDF (aNDF)

\begin{tabular}{|c|c|c|c|c|c|}
\hline Method $^{1}$ & Corn silage & Grass silage & Barley & Beet pulp & Rapeseed cake \\
\hline & \multicolumn{5}{|c|}{$\mathrm{D}_{0}=$ Potential degradable aNDF $(\mathrm{g} / \mathrm{g}$ of $\mathrm{DM})$} \\
\hline IS & $0.277^{\mathrm{b}}$ & $0.318^{\mathrm{b}}$ & $0.106^{\mathrm{b}}$ & $0.405^{\mathrm{a}}$ & 0.094 \\
\hline IVa & $0.242^{\mathrm{c}}$ & $0.327^{\mathrm{ab}}$ & $0.144^{\mathrm{a}}$ & $0.365^{\mathrm{b}}$ & 0.113 \\
\hline IVn & $0.301^{\mathrm{a}}$ & $0.341^{\mathrm{a}}$ & $0.166^{\mathrm{a}}$ & $0.378^{\mathrm{ab}}$ & 0.113 \\
\hline \multirow[t]{2}{*}{$P$ method } & 0.0001 & 0.0005 & $<0.0001$ & 0.0002 & $0.0440^{3}$ \\
\hline & \multicolumn{5}{|c|}{$\mathrm{k}_{\mathrm{d}}=$ Fractional rate of aNDF degradation $($ per $\mathrm{h})$} \\
\hline IS & $0.0278^{\mathrm{b}}$ & $0.0542^{\mathrm{b}}$ & $0.0690^{\mathrm{b}}$ & $0.0801^{\mathrm{b}}$ & $0.1034^{\mathrm{b}}$ \\
\hline IVa & $0.0592^{\mathrm{a}}$ & $0.0942^{\mathrm{a}}$ & $0.1712^{\mathrm{a}}$ & $0.1035^{\mathrm{b}}$ & $0.1067^{\mathrm{b}}$ \\
\hline IVn & $0.0579^{\mathrm{a}}$ & $0.1087^{\mathrm{a}}$ & $0.1676^{\mathrm{a}}$ & $0.2911^{\mathrm{a}}$ & $0.2619^{\mathrm{a}}$ \\
\hline \multirow[t]{2}{*}{$P$ method } & 0.0001 & $<0.0001$ & $<0.0001$ & $<0.0001$ & 0.0145 \\
\hline & \multicolumn{5}{|c|}{$\mathrm{I}=$ Indegradable aNDF $(\mathrm{g} / \mathrm{g}$ of $\mathrm{DM})$} \\
\hline IS & $0.101^{\mathrm{c}}$ & $0.065^{\mathrm{b}}$ & $0.072^{\mathrm{b}}$ & $0.015^{\mathrm{b}}$ & 0.135 \\
\hline IVa & $0.172^{\mathrm{a}}$ & $0.096^{\mathrm{a}}$ & $0.088^{\mathrm{a}}$ & $0.114^{\mathrm{a}}$ & 0.133 \\
\hline IVn & $0.116^{\mathrm{b}}$ & $0.089^{a}$ & $0.066^{\mathrm{b}}$ & $0.108^{\mathrm{a}}$ & 0.133 \\
\hline$P$ method & \multicolumn{5}{|c|}{$\mathrm{L}=$ Lagtime $\left(\mathrm{h}^{-1}\right)$} \\
\hline IS & $3.97^{\mathrm{b}}$ & $2.34^{\mathrm{b}}$ & 0.00 & $4.06^{\mathrm{b}}$ & 2.54 \\
\hline IVa & $12.07^{\mathrm{a}}$ & $9.10^{\mathrm{a}}$ & 0.00 & $7.80^{\mathrm{a}}$ & 3.48 \\
\hline IVn & $0.85^{\mathrm{c}}$ & $1.43^{\mathrm{b}}$ & 0.00 & $3.99^{\mathrm{b}}$ & 1.75 \\
\hline \multirow[t]{2}{*}{$P$ method } & $<0.0001$ & $<0.0001$ & $-^{2}$ & $<0.0001$ & 0.4561 \\
\hline & \multicolumn{5}{|c|}{$\mathrm{ED}=$ Effective aNDF degradation $(\mathrm{g}$ of aNDF/g of DM) } \\
\hline IS & $0.147^{\mathrm{b}}$ & $0.221^{\mathrm{b}}$ & $0.082^{\mathrm{b}}$ & $0.297^{\mathrm{b}}$ & 0.075 \\
\hline IVa & $0.139^{b}$ & $0.223^{\mathrm{b}}$ & $0.129^{\mathrm{a}}$ & $0.256^{\mathrm{c}}$ & 0.088 \\
\hline IVn & $0.218^{\mathrm{a}}$ & $0.280^{\mathrm{a}}$ & $0.148^{\mathrm{a}}$ & $0.326^{\mathrm{a}}$ & 0.101 \\
\hline$P$ method & $<0.0001$ & 0.0001 & $<0.0001$ & $<0.0001$ & $0.0093^{3}$ \\
\hline
\end{tabular}

${ }^{\mathrm{a}-\mathrm{c}}$ Values within a column with different superscript letters differ at $P<0.05$.

${ }^{1} \mathrm{IS}=$ in situ; IVa $=$ in vitro with media $\mathrm{pH}$ adjusted to 6.0 using citric acid; IVn $=$ in vitro with media $\mathrm{pH}$ of 6.8 .

${ }^{2}$ Estimates of L for barley met the boundary conditions, and therefore the statistical analysis was inappropriate.

${ }^{3}$ Mean separation did not detect significant differences among methods for rapeseed cake, but $t$-test comparisons indicated that the IS method tended to give larger estimates of $\mathrm{D}_{0}$ compared with $\operatorname{IVn}(P=$ $0.1)$ and IVa $(P=0.1)$, and there was a tendency that the IVn method resulted in larger ED compared with the IS $(P=0.07)$. 
Table 4. Influence of grinding on the degradation parameters of amylase-treated NDF (aNDF)

\begin{tabular}{|c|c|c|c|c|c|}
\hline Grinding & Corn silage & Grass silage & Barley & Beet pulp & Rapeseed cake \\
\hline & \multicolumn{5}{|c|}{$\mathrm{D}_{0}=$ Potential degradable aNDF (g/g of DM) } \\
\hline $1 \mathrm{~mm}$ & 0.260 & 0.322 & $0.108^{\mathrm{b}}$ & 0.369 & 0.109 \\
\hline $2 \mathrm{~mm}$ & 0.272 & 0.328 & $0.130^{\mathrm{b}}$ & 0.391 & 0.105 \\
\hline $4 \mathrm{~mm}$ & 0.275 & 0.328 & $0.177^{\mathrm{a}}$ & 0.388 & \\
\hline $8 \mathrm{~mm}$ & 0.284 & 0.337 & & & \\
\hline \multirow[t]{2}{*}{$P$ grinding } & 0.1908 & 0.0544 & $<0.0001$ & $0.0089^{2}$ & 0.4649 \\
\hline & \multicolumn{5}{|c|}{$\mathrm{k}_{\mathrm{d}}=$ Fractional rate of aNDF degradation $\left(\mathrm{h}^{-1}\right)$} \\
\hline $1 \mathrm{~mm}$ & 0.0562 & 0.0959 & $0.1142^{\mathrm{b}}$ & 0.1607 & 0.1541 \\
\hline $2 \mathrm{~mm}$ & 0.0499 & 0.0771 & $0.1223^{\mathrm{b}}$ & 0.1475 & 0.1606 \\
\hline $4 \mathrm{~mm}$ & 0.0462 & 0.0834 & $0.1713^{\mathrm{a}}$ & 0.1665 & \\
\hline $8 \mathrm{~mm}$ & 0.0408 & 0.0863 & & & \\
\hline \multirow[t]{2}{*}{$P$ grinding } & 0.1616 & 0.0542 & 0.0072 & 0.7044 & 0.8548 \\
\hline & \multicolumn{5}{|c|}{$\mathrm{I}=$ Indegradable aNDF (g/g of DM) } \\
\hline $1 \mathrm{~mm}$ & $0.120^{\mathrm{b}}$ & 0.079 & 0.075 & 0.082 & 0.133 \\
\hline $2 \mathrm{~mm}$ & $0.124^{\mathrm{b}}$ & 0.079 & 0.076 & 0.072 & 0.134 \\
\hline $4 \mathrm{~mm}$ & $0.130^{\mathrm{b}}$ & 0.087 & 0.076 & 0.082 & \\
\hline $8 \mathrm{~mm}$ & $0.144^{\mathrm{a}}$ & 0.091 & & & \\
\hline \multirow[t]{2}{*}{$P$ grinding } & 0.0298 & $0.0048^{2}$ & 0.9362 & 0.1794 & 0.8592 \\
\hline & \multicolumn{5}{|c|}{$\mathrm{L}=$ Lagtime $(\mathrm{h})$} \\
\hline $1 \mathrm{~mm}$ & 6.06 & $4.25^{\mathrm{ab}}$ & 0.000 & 5.67 & 2.55 \\
\hline $2 \mathrm{~mm}$ & 5.77 & $3.30^{\mathrm{b}}$ & 0.000 & 4.45 & 2.62 \\
\hline $4 \mathrm{~mm}$ & 6.00 & $4.65^{\mathrm{ab}}$ & 0.000 & 5.72 & \\
\hline $8 \mathrm{~mm}$ & 4.69 & $4.94^{\mathrm{a}}$ & & & \\
\hline \multirow[t]{2}{*}{$P$ grinding } & 0.7076 & 0.0218 & $-^{1}$ & $0.0307^{2}$ & 0.9517 \\
\hline & \multicolumn{5}{|c|}{$\mathrm{ED}=$ Effective aNDF degradation $(\mathrm{g}$ of aNDF/g of DM) } \\
\hline $1 \mathrm{~mm}$ & 0.166 & 0.241 & $0.090^{\mathrm{b}}$ & 0.286 & 0.091 \\
\hline $2 \mathrm{~mm}$ & 0.170 & 0.240 & $0.111^{\mathrm{b}}$ & 0.297 & 0.086 \\
\hline $4 \mathrm{~mm}$ & 0.166 & 0.239 & $0.157^{\mathrm{a}}$ & 0.295 & \\
\hline $8 \mathrm{~mm}$ & 0.171 & 0.245 & & & \\
\hline$P$ grinding & 0.6725 & 0.4172 & $<0.0001$ & 0.4131 & 0.3261 \\
\hline
\end{tabular}

except for RC where significant difference between methods was only found for $\mathrm{k}_{\mathrm{d}}$. In Table 3 , influences of method on individual degradation parameters and the ED are summarized. Within the IVa and IVn methods the sum of the $\mathrm{D}_{0}$ and I fractions were approximately equal, but the sum was lower $(P<0.01)$ for all feeds except RC using the IS method due to losses during washing of zero-hour bags. There was a tendency for $\mathrm{D}_{0}$ to be lower and I to be higher for IVa compared with IVn with all feeds except RC, but only the differences for CS were significant $(P<0.05)$. Grant and Mertens (1992b) observed that IV $\mathrm{pH}$ did not influence the $\mathrm{D}_{0}$ and I of forages incubated without starch at different buffer $\mathrm{pH}(6.8,6.2$, and 5.8) in contrast to our $\mathrm{CS}$ results. However, they observed that adding starch increased I at all IV $\mathrm{pH}$. The inoculum donor for their study was a single nonlactating cow fed forage only, compared with our study which used a composite inoculum from 4 lactating cows fed a mixed forage-concentrate ration. Differences in the microbial organisms between inoculum sources may explain the discrepancy between the results of the 2 experiments.
Method IVa decreased $\mathrm{k}_{\mathrm{d}}(P<0.05)$ for $\mathrm{BP}$ and $\mathrm{RC}$ compared with IVn, whereas no significant effect was found for CS, GS, and B. Although we observed no difference in $\mathrm{k}_{\mathrm{d}}$ of CS and GS between in vitro $\mathrm{pH} 6.0$ versus pH of 6.7, Grant and Mertens (1992b) found that $\mathrm{k}_{\mathrm{d}}$ of NDF was reduced in forages when samples were incubated at $\mathrm{pH} 5.8$, compared with incubation at $\mathrm{pH}$ 6.2 and 6.8 , especially when starch was included in the fermentations. During IVa incubation of GS, average $\mathrm{pH}$ was above 6.0 (Figure 2), which might explain the lack of differences in $\mathrm{k}_{\mathrm{d}}$ between IVa and IVn for this feed. We observed that $k_{d}$ was less for IS than for IVn in all samples. The $k_{d}$ of the IS method was also less than that observed for the IVa method for B, CS, and GS. Lower $\mathrm{k}_{\mathrm{d}}$ from IS incubation compared with IV incubation was also found by Dewhurst et al. (1995). The $\mathrm{pH}$ magnitude (averaging 5.8 and 6.0 for IS and IVa, respectively) and pattern of IVa and IS fermentations were different (Figures 2 and 3), which may explain the lower $\mathrm{k}_{\mathrm{d}}$ of the IS method. Huhtanen et al. (1995) observed that rates of digestion measured IS were less than those calculated from ruminal evacua- 
tion. They suggested that slower rates of digestion in situ might be related to hindered flow of microorganisms, nutrients, and buffers through the small pores and open area of IS bags.

The $\mathrm{L}$ of the IVa method were higher than those of IS or IVn methods for CS, GS, and BP (numerically higher for RC). The $\mathrm{L}$ of the IS method was similar to the IVn method for all feeds except CS. Reducing IV buffer $\mathrm{pH}$ from 6.7 to 6.0 in present experiment increased L in agreement with Grant and Mertens (1992b), but the effect was larger. Increasing $\mathrm{L}$ due to decreasing $\mathrm{pH}$ could be related to reduced/delayed microbial adherence. Mourino et al. (2001) observed increased $\mathrm{L}$ and decreased adherence of bacteria to cellulose within $6 \mathrm{~h}$ of inoculation as the $\mathrm{pH}$ of the IV medium decreased from 6.5 to 5.5.

The ED of aNDF was calculated to determine the combined effects of $\mathrm{D}_{0}, \mathrm{k}_{\mathrm{d}}$, and $\mathrm{L}$ on degradation (Mertens, 1977; Stensig, et al., 1994) for each method. The ED of the IS method was lower than that of the IVn method for all feeds except RC, which also was numerically lower. The ED of CS and GS was similar for IS and IVa methods, but IS was lower than IVa for barley and higher for BP. The ED of aNDF in RC was not different among methods.

Differences in aNDF residue amounts after IS and IV incubation in this experiment can be divided in 2 groups: 1) differences mainly due to technical conditions and 2) differences mainly due to biological conditions.

Compared with IV incubation in flasks, the amount of aNDF residues after IS incubation in Dacron bags may be reduced due to particle losses from the bags during incubation and washing after incubation (Hvelplund and Weisbjerg, 2000). Particle loss is probably the main reason for the lower sum of $I$ and $D_{0}$ within feed, obtained for the IS compared with the IV methods. When calculating degradability, residues of the feed fraction of interest (e.g., DM, OM, aNDF) after incubation are related to the initial content of the fraction. Using the IS incubation method, particle losses can lead to underestimation of the $\mathrm{NDF}_{0}$ content, which could result in an overestimation of the degradabilities. However, there is no indication that the ED obtained from the IS incubation were overestimated compared with the IV results obtained in this experiment. When using bags with a pore size of $42 \mu \mathrm{m}$ in combination with feed samples that were either not ground or ground to pass a screen with $6-\mathrm{mm}$ openings for IS incubation and compared with samples ground to pass a 1-mm screen for the IV incubation, Dewhurst et al. (1995) found higher OM degradability for most feeds when estimated by IS incubation compared with IV incubation. Investigating DM degradability of untreated and ammoniatreated barley straw, Graham and Åmen (1983) found higher degradability of DM after $168 \mathrm{~h}$ of IS incubation compared with IV incubation. In the experiment of Graham and Åmen (1983), straw was ground to pass a 1$\mathrm{mm}$ screen, and nylon bags with a pore size of $20 \mu \mathrm{m}$ was used for IS incubation. The difference in degradability was explained by inhibited IV digestion due to build-up of fermentation end products, in combination with higher particle losses from the IS incubation.

The experiments of Varel and Kreikemeier (1995), Robinson et al. (1999), and Spanghero et al. (2003) suggest that some differences between IV and IS incubations may be due to biological factors; however, their results are contradictory. Varel and Kreikemeier (1995) compared NDF degradation parameters obtained from IV and IS incubation, correcting the NDF residues from IS incubation for particle loss of $3 \%$. They incubated samples of neutral detergent extracted bromegrass and alfalfa hay ground in a shear mill to pass a 1-mm screen and used Dacron bags with a pore size of $53 \mu \mathrm{m}$ for the IS incubation. Their experiment revealed potential NDF degradabilities which were $6 \%$ lower and average $\mathrm{k}_{\mathrm{d}}$ that were $0.030 \mathrm{~h}^{-1}$ (approximately 48\%) lower for IV compared with results obtained from the IS method. Varel and Kreikemeier (1995) also found lag time to be significantly higher for the IV method compared with the IS method. They explained the results with reduced activity of the rumen fluid inoculum because the rumen fluid is diluted 1:5 when inoculated into the tubes containing IV buffer solution. However, using a 1:4 ratio of ruminal fluid to medium, we observed shorter lags and faster $\mathrm{k}_{\mathrm{d}}$ for IVn than for IS when the same cows were used as IV donors and for IS incubations. After $48 \mathrm{~h}$ of incubation, Robinson et al. (1999) found higher NDF degradability when whole crop forages (ground to pass a 2-mm screen) were incubated IV using the a rotating jar IV system compared with IS. This agrees with our observations when we compare IS to IVn. In a similar experiment, Spanghero et al. (2003) also found higher NDF degradation after $48 \mathrm{~h}$ of incubation using a rotating jar IV system compared with IS, but their IS samples were ground more coarsely (4-mm screen) than those incubated IV (1-mm screen). These results and the variable responses in NDF degradation among feeds that we observed suggest that several factors and their interactions are responsible for differences between IS and IV methods.

It is interesting that when all degradation characteristics are combined to estimate ED, the IVa method agrees more closely with IS than did IVn. However, as discussed by Huhtanen et al. (2006), $\mathrm{pH}$ is one of many extrinsic factors influencing NDF degradation when measured using the IS. In addition to particle loss and $\mathrm{pH}$, other differences in fermentation methods could contribute to differences in degradation characteristics 
between IS and IV measurements (e.g., differences in mixing of feed particles, concentration of individual VFA, and osmotic pressure in the fermentation bag or vessel).

In the present experiment, $\mathrm{L}$ appeared to be related to the magnitude and pattern of $\mathrm{pH}$ differences among methods (IVn $<$ IS $<$ IVa). Inoculum used for the IVn incubation was prepared from rumen contents originating from the cows used for the IS incubation and fermented with substrates in a buffer solution (Goering and Van Soest, 1970) designed to obtain stable $\mathrm{pH}$ of 6.8 , which is thought to be optimal for fiber degradation (Grant and Mertens, 1992b). Lowest L was observed for IVn, which had the theoretical optimum $\mathrm{pH}$ for fermentation. Feed level and ration composition influence rumen microbial environment and degradation of NDF when $\mathrm{pH}$ declines to 6.0-6.2 (Huhtanen et al., 2006). In the present experiment, the cows used for the IS incubation and as IV inocula doners were fed TMR at production levels of intake. Average rumen $\mathrm{pH}$ of the 4 cows was 5.8, but there was a large diurnal variation in $\mathrm{pH}$ (Figure 3) during IS incubations compared with $\mathrm{pH}$ during IV incubations. For $67,42,42$, and $0 \%$ of the $24-\mathrm{h}$ period rumen $\mathrm{pH}$ was above 6.0 for the 4 cows, respectively. In comparison, $\mathrm{pH}$ after IVa incubation was below 6.3 during the whole incubation interval for all feeds and below 6.0 for CS, B, and BP. The L was significantly higher for the IVa method compared with the IS method, which could reflect a more pronounced delay in microbial adherence under incubation at continuously low $\mathrm{pH}$ (IVa), compared with incubation at low, but variable, $\mathrm{pH}$ (IS). Mourino et al. (2001) observed that the $\mathrm{pH}$ at which the inoculation occurred had a significant impact on lag time. Thus, L measured in vitro at low $\mathrm{pH}$ may be increased compared with IS at similar $\mathrm{pH}$ because the $\mathrm{pH}$ of the in vitro system is low at the time of inoculation and does not vary during fermentation as it does in the animal during bouts of rumination.

Degradation parameters for NDF are dependent on the incubation method, and therefore the method selected must be compatible with the way the ration evaluation system uses NDF degradation parameters. For feed evaluation, it is important that digestion characteristics representing the intrinsic potential of the feed are measured in a way in which fermentation system is not limiting. It appears that IV methods conducted at optimal $\mathrm{pH}$ obtain the largest potentially degradable fractions and rates that should be or approach the intrinsic limitation of the feed. However, if these degradation parameters are to be used in models of animal performance, they may need to be adjusted to reflect the conditions in the rumen. Conversely, degradation characteristics measured in suboptimal IS or IV sys- tems represent a confounding of system and feed limitations. They will be useful in models only if the conditions under which they are measured are compatible with model assumptions and function. Because suboptimal conditions cannot be fully described with current state of knowledge, degradation characteristics measured under suboptimal conditions can only be compared within method or experiment and have limited utility in describing potential nutritive value of feeds.

Influence of Grinding. Influences of grinding on degradation parameters found in the present experiment are summarized in Table 4 as mean values of the 3 methods. Only parameters $\mathrm{D}_{0}$ and $\mathrm{k}_{\mathrm{d}}$ in $\mathrm{B}, \mathrm{I}$ in CS, and $L$ in GS was influenced by sample grinding. The $B$ had the largest particle size of all the feeds when grinded at screen size 2 and $4 \mathrm{~mm}$. Increasing $\mathrm{D}_{0}$ and decreasing $\mathrm{kd}$ of $\mathrm{B}$ is probably an artifact of incomplete starch extraction from the $\mathrm{aNDF}_{0}$ of $\mathrm{B}$ ground at large screen size $(4 \mathrm{~mm})$ compared with small screen sizes ( 1 and $2 \mathrm{~mm}$ ). The I found in CS was significantly higher when grinding at screen size $8 \mathrm{~mm}$ compared with grinding at screen size 4,2 , and $1 \mathrm{~mm}$. It indicates incomplete extraction of neutral detergent soluble material from large particles. When no similar effects were seen for GS, it might be due to the fact that particle size of GS ground at $8 \mathrm{~mm}$ was lower than the corresponding particle size obtained in CS. Grinding significantly affected L in GS, but the effect was not consistent with development in particle size. Grinding had no influence on $\mathrm{L}$ in $\mathrm{BP}$ and $\mathrm{RC}$, which could be due to the typically low L observed in concentrate feeds.

Udén (1992) suggested that grinding of feed samples and the resulting reduction in feed particle size can be expected to increase the $k_{d}$ and decrease $L$, as a result of increased surface area for microbial adhesion. Particle size interacts with method used for measurement of aNDF degradation because of potential losses from IS bags, but the biological impact of feed particle size on degradation characteristics is less clear. Robles et al. (1980) and Belyea et al. (1983) observed no effect of grinding particle size on rates of digestion. Mertens (1993) postulated that particle size may not be a major impediment for digestion because feed particles are porous rather than solid, which dramatically affects the particle size and surface area relationship. Huntington and Givens (1995) suggest that particle size might interact with incubation time because the effects of particle size are evident only at short incubation times.

Based on results from this experiment, there is little indication that the degradation characteristics of NDF are influenced by particle size when ground through screens with 1- to 8-mm openings other than effects related to the neutral detergent extraction. Although there must be situations in which the physical form of 
the feed limits or defines its degradation characteristics, it appears that increasing the particle size of ground samples had limited impact on the degradation of the feeds we evaluated.

\section{CONCLUSIONS}

Choice of fermentation methods-in vitro or in situwas more important than grinding screen size on estimates obtained for feed aNDF degradation parameters. However, the mean particle size obtained from grinding through different screen sizes contributed to the difference between methods because it influenced the particle loss from the bags used for IS incubation.

The confounding between collection of inoculum for the IVa method and time was assumed to be of minor importance because donor cows were fed the same rations during the entire experimental period, and the variation of the difference between aNDF residues using the IVn and IVa method, respectively, did not seem to be systematically related to time interval between inoculum collections.

The IS method resulted in smaller fractions of potentially degradable and indegradable aNDF, possibly due to particle losses. In addition, the IS method had slower rates of digestion for all substrates, ascribed to variation in ruminal environment or fermentation conditions within in situ bags. The small differences in rates of degradation between IVn and IVa for forages suggests that the slower rate of digestion measured IS did not appear to be related to average $\mathrm{pH}$ during incubation.

Lag time increased markedly for all feeds when the $\mathrm{pH}$ of in vitro incubation was lowered from 6.8 to 6.0. The IVa method generated longer lag times for most feeds compared with the IS method, suggesting that the inhibitory effect of low $\mathrm{pH}$ on initiation of aNDF degradation is stronger when using the IV compared with the IS method. The diurnal variation in $\mathrm{pH}$ IS may be an important factor moderating the effects of IS $\mathrm{pH}$ on $\mathrm{L}$.

Although the effect of fermentation methods on the pattern of degradation characteristics varied considerably among feeds, the extent of degradation of the IS method was related more consistently to IVa than to the IVn method. It appears that the IVn method, which obtained the largest extent of degradation for all feeds, estimates the degradation characteristics that represent the potential degradation of feeds (intrinsic feed value) that is important in feed evaluation for ruminants.

\section{REFERENCES}

Ankom Technology. 2005. Method for determining neutral detergent fiber (aNDF). Ankom Technology, Macedon, NY.
AOAC. 2000. Official Methods of Analysis. 17th ed. Assoc. Off. Agric. Chem. Washington, DC.

ASAE. 2003. Method of Determining and Expressing Fineness of Feed Materials by Sieving. Am. Soc. Agric. Eng., standards no. S319.3.

Belyea, R. L., M. B. Foster, and G. M. Zinn. 1983. Effects of delignification on in vitro digestion of alfalfa cellulose. J. Dairy Sci. 66:1277-1281.

Dewhurst, R. J., D. Hepper, and A. J. F. Webster. 1995. Comparison of in sacco and in vitro techniques for estimating the rate and extent of rumen fermentation of a range of dietary ingredients. Anim. Feed Sci. Technol. 51:211-229.

Eriksson, T., E. Lindberg, O. M. Harstad, L. Bævre, B. L. Olafsson, M. R. Weisbjerg, and R. Thøgersen. 2007. NorFor in sacco standard. Sept. 10, 2007. NorFor, Uppsala, Sweden.

Goering, H. K., and P. J. Van Soest. 1970. Forage Fiber Analysis (Apparatus, Reagents, Procedures, and Some Applications). Agric. Handbook No. 379. ARS-USDA, Washington, DC.

Graham, H., and P. Åmen. 1983. A comparison between degradation in vitro and in sacco of constituents of untreated and ammonia treated barley straw. Anim. Feed Sci. Technol. 10:199-211.

Grant, R. J., and D. R. Mertens. 1992a. Development of buffer systems for $\mathrm{pH}$ control and evaluation of $\mathrm{pH}$ effects on fiber digestion in vitro. J. Dairy Sci. 75:1581-1587.

Grant, R. J., and D. R. Mertens. 1992b. Influence of buffer $\mathrm{pH}$ and raw corn starch addition on in vitro fiber digestion kinetics. J. Dairy Sci. 75:2762-2768.

Hansen, B. 1989. Determination of nitrogen as elementary N, as an alternative to Kjeldahl. Acta. Agric. Scand. A Anim. Sci. 39:113-118.

Huhtanen, P., S. Ahvenjärvi, M. R. Weisbjerg, and P. Nørgaard. 2006. Digestion and passage of fibre in ruminants. Pages $87-135$ in Ruminant Physiology-Digestion metabolism and impact of nutrition on gene expression, immunology and stress. Sejrsen, K., T. Hvelplund, and M. O. Nielsen, ed. Wageningen Academic Publishers, Wageningen, the Netherlands.

Huhtanen, P., S. Jaakkola and U. Kukkonen. 1995. Ruminal plant cell wall digestibility estimated from digestion and passage kinetics utilizing mathematical models. Anim. Feed Sci. Technol. $52: 159-173$.

Huntington, J. A., and D. I. Givens. 1995. The in situ technique for studying the rumen degradation of feeds: A review of the procedure. Nutr. Abs. Rev. Ser. B 65:64-93.

Hvelplund, T., and M. R. Weisbjerg. 2000. In Situ Techniques for the Estimation of Protein Degradability and Postrumen Availability. Pages 233-258 in Forage evaluation in Ruminant Nutrition. D. I. Givens, E. Owen, R. F. E. Axford, and H. M. Omed, ed. CAB International Publishing, Wallingford, UK.

Jasaitis, D. K., J. E. Wohlt, and J. L. Evans. 1987. Influence of feed ion content on buffering capacity of ruminant feedstuffs in vitro. J. Dairy Sci. 70:1391-1403.

Knudsen, K. E. B., P. Åman, and B. O. Eggum. 1987. Nutritive value of Danish-grown barley varieties. J. Cereal Sci. 2:173-186.

Lund, P., M. R. Weisbjerg, and T. Hvelplund. 2007. Digestible NDF is selectively retained in the rumen of dairy coes compared to indigestible NDF. Anim. Feed Sci. Technol. 134:1-17.

McDonald, I. 1981. A revised model for the estimation of protein degradability in the rumen. J. Agric. Sci. Camb. 96:251-252.

Mertens, D. R. 1977. Dietary fiber components: Relationship to the rate and extent of ruminal digestion. 17th Annual Ruminant Nutr. Conf. Symp. Metabolism of Dietary Components in the Rumen Ecosystem. Fed. Proc. 36:187-192.

Mertens, D. R. 1993. Kinetics of cell wall digestion and passage in ruminants. Pages 535-570 in Forage Cell Wall Structure and Digestibility. R. D. Hatfield, H. G. Jung, J. Ralph, D. R. Buxton, D. R. Mertens, and P. J. Weimar, ed. Am. Soc. Agron. Inc., Crop Sci. Soc. Am. Inc., Soil Sci. Am. Inc., Madison, WI.

Mertens, D. R. 2002. Gravimetric determination of amylase-treated neutral detergent fiber in feeds with refluxing in beakers or crucibles. Collaborative study. J. AOAC Int. 85:1217-1240.

Michalet-Doreau, B., and P. Cerneau. 1991. Influence of foodstuff particle size on in situ degradation of nitrogen in the rumen. Anim. Feed Sci. Technol. 35:69-81. 
Mourino, F., R. Akkarawongsa, and P. J. Weimer. 2001. Initial pH as determinant of cellulose digestion rate by mixed ruminal microorganisms in vitro. J. Dairy Sci. 84:848-859.

Nocek, J. E. 1988. In situ and other methods to estimate ruminal protein and energy digestibility: A review. J. Dairy Sci. 71:2051-2069.

Robinson, P. H., M. Campbell Mathews, and J. G. Fadel. 1999. Influence of storage time and temperature on in vitro digestion of neutral detergent fibre at $48 \mathrm{~h}$, and comparison to $48 \mathrm{~h}$ in sacco neutral detergent fibre digestion. Anim. Feed Sci. Technol. 80:257-266

Robles, A. Y., R. L. Belyea, F. A. Martz, and M. F. Weiss. 1980. Effect of particle size upon digestible cell wall and rate of in vitro digestion of alfalfa and orchardgrass forages. J. Anim. Sci. 51:783-790.

Rymer, C., J. A. Huntington, B. A. Williams, and D. I. Givens. 2005. In vitro cumulative gas production techniques: History, methodological considerations and challenges. Anim. Feed Sci. Technol. 123:9-30.

SAS Institute. 2000. SAS/STAT User's guide, Version 8. SAS Institute Inc., Cary, NC.

Spanghero, M., S. Boccalon, L. Gracco, and L. Gruber. 2003. NDF degradability of hays measured in situ and in vitro. Anim. Feed Sci. Technol. 104:201-208.
Stensig, T., M. R. Weisbjerg, and T. Hvelplund. 1994. Estimation of ruminal digestibility of NDF from in sacco degradation and rumen fractional outflow rate. Acta Agric. Scand., Sect. Anim. Sci. 44:96-109.

Stoldt, W. 1952. Vorslag zur Vereinheitlichung der Fettbestimmung in Lebensmitteln. Fette u. Seifen 54:206-207.

Udén, P. 1992. The influence of leaf and stem particle size in vitro and of sample size in sacco on neutral detergent fiber fermentation kinetics. Anim. Feed Sci. Technol. 37:85-97.

Vanzant, E. S., R. C. Cochran, and E. C. Titgemeyer. 1998. Standardization of in situ techniques for ruminant feedstuff evaluation. J. Anim. Sci. 76:2717-2729.

Varel, V. H., and K. K. Kreikemeier. 1995. Technical Note: Comparison of in vitro and in situ digestibility methods. J. Anim. Sci. 73:578-582.

Weisbjerg, M. R., and T. Hvelplund. 2005. Current status of using in situ estimates in feedstuff evaluation for dairy cows in the Nordic countries. Übers. Tierernähr. 33:157-167.

Weisbjerg, M. R., and P. Lund. 2004. How do we interpret in situ degradation profiles? NorFor mini-seminar "Methods for prediction of degradability characteristics of feeds for ruminants". Küngsengen, Swedish University of Agriculture, Uppsala, Sweden. 